\title{
Murine gammaherpes virus as a cofactor in the development of pulmonary fibrosis in bleomycin resistant mice
}

\author{
S.S. Lok*, Y. Haider*, D. Howell ${ }^{\#}$, J.P. Stewart", P.S. Hasleton" ${ }^{\#}$, J.J. Egan ${ }^{+}$
}

\begin{abstract}
Murine gammaherpes virus as a cofactor in the development of pulmonary fibrosis in bleomycin resistant mice. S.S. Lok, Y. Haider, D. Howell, J.P. Stewart, P. S. Hasleton, J.J. Egan. (C) ERS Journals Ltd 2002.

ABSTRACT: Studies of human tissue have suggested an association between productive Epstein Barr virus and idiopathic pulmonary fibrosis (IPF). However, a pathogenic role for the virus has not been established. This study was undertaken to develop an animal model, which would explore the association between viral infection and pulmonary fibrosis.

BALB/c mice $(n=30)$, resistant to bleomycin, were primed with murine gammaherpesvirus 68 and then given intraperitoneal bleomycin. The mice were sacrificed at 28 days after bleomycin and their lungs assessed histologically and biochemically. Lung pathology was scored $0-3$ for fibrotic and inflammatory change.

BALB/c mice given virus and bleomycin showed more lung fibrosis (median score 2.2) compared to those given bleomycin alone (median 0 ), virus alone (median 0.2 ) or phosphate-buffered saline (PBS) control (median 0). Similarly mice given both virus and bleomycin showed more lung inflammation (median score 1.9) compared to those given bleomycin (median 0.5), virus (median 0.8), or PBS control (median 0.2). There was a significant difference in collagen content between the bleomycin and virus group (mean $1.86 \mathrm{mg}$ ) compared to the belomycin alone group (mean $1.52 \mathrm{mg}$ ).

These results suggest that virus alone does not result in pulmonary fibrosis but that replicating virus in the presence of an exogenous injury may promote the development of pulmonary fibrosis.
\end{abstract}

Eur Respir J 2002; 20: 1228-1232.
*North West Lung Research Centre, Wythenshawe Hospital, Southmoor Road, Manchester, "Raynes Institute, University College London, London, 'Dept of Veterinary Pathology, University of Edinburgh, Summerhall, Edinburgh, and ${ }^{+}$The Mater Misericordiae Hospital, Eccles Street, Dublin, Ireland, UK.

Correspondence: J.J. Egan, Dept of Respiratory Medicine, The Mater Misericordiae Hospital, Eccles Street, Dublin 7, Ireland.

Fax: 35316605451

E-mail: jegan@mater.ie

Keywords: Bleomycin murine gammaherpes virus pulmonary fibrosis

Received: August 212001

Accepted after revision: March 222002
Idiopathic pulmonary fibrosis (IPF) is a disease of unknown aetiology with a poor prognosis. Viruses have the potential to modify cellular function resulting in disease. For example, Epstein Barr virus (EBV), a herpes virus, is an aetiological factor in Burkitts lymphoma and nasopharyngeal carcinoma [1]. An association of IPF with EBV has been reported [2-5] though a causal relationship has not been established.

Serological studies have shown a relationship of active EBV with IPF [3, 6]. Tissue based analyses have identified EBV productive cycle antigens in type II epithelial cells of IPF patients [7, 8] as well as EBV deoxyribonucleic acid $[9,10]$ but whether the virus is a passenger or has a pathogenic role is unclear.

An understanding of the role of EBV in pulmonary fibrosis would be facilitated by the development of an animal model. Unfortunately, EBV has a limited host range restricting its use in animals. However, murine gammaherpes virus 68 (MHV) is a closely related mouse virus and is effectively the murine equivalent of EBV [11-13]. There are similarities in the genome with the synthesis of productive cycle antigens with strong homology during replication. Following acute infection the clinical disease is similar in their respective hosts.

Bleomycin-induced fibrosis in an animal model is the common method for studying fibrosis but this has several limitations. Mice resistant to bleomycin were chosen to investigate whether viral infection would result in bleomycin-induced fibrosis. This study was undertaken to explore the role of a herpes virus as a cofactor in the development of pulmonary fibrosis in a host exposed to an exogenous injury to which it is normally resistant.

\section{Methods}

\section{Animals}

All experiments were performed using bleomycin resistant BALB/c mice aged 5-6 weeks and weighing between 21-29 g. Mice were housed in plastic cages on hardwood shaving, with free access to laboratory chow and water, and room conditions appropriate to Home Office guidelines.

\section{Experimental protocol}

Two sets of experiments were performed, one for histological evaluation $(n=30)$ and the second for estimation of collagen content $(n=28)$. Mice in each experiment were divided into four groups as follows. 
1) Group B (Bleomycin only): given phosphatebuffered saline (PBS) transnasally but bleomycin intraperitoneally. 2) Group V (virus only): given MHV transnasally but PBS intraperitoneally. 3) Group BV (bleomycin and virus): given MHV transnasally and bleomycin intraperitoneally. 4) Group C (controls): given PBS transnasally and intraperitoneally.

On day 1, MHV was given transnasally, at a dose of $4 \times 10^{5}$ platform units under anaesthesia with halothane. On day 8, intraperitoneal bleomycin was administered (without sedation), at a dose of $40 \mathrm{mg} \cdot \mathrm{kg}^{-1} \cdot \mathrm{day}^{-1}$ on alternate days for 3 days (cumulative dose of $120 \mathrm{mg} \cdot \mathrm{kg}^{-1}$ ). PBS was given as a control substance. The mice were reviewed on a daily basis and those that died prematurely or were showing evidence of distress were sacrificed early and examined. On day 36, all surviving mice were sacrificed by a lethal dose of intraperitoneal pentobarbitone, and their lungs were dissected and removed.

\section{Histological examination}

After dissection the lungs were inflated with formalin by direct injection. The lungs were further fixed and stored in formalin until ready for routine dehydration and embedding in paraffin wax.

Sections of 3-5 mm were obtained from the paraffin wax-preserved lung tissue and stained with haemotoxylin and eosin. A histopathologist (P.S. Hasleton), blinded to the groups, scored the degree of fibrosis and inflammation according to a simplified modification of a published scoring system [14]. The sections were systematically scanned at low power. Fibrosis and inflammation were scored individually from $0-3$ according to the percentage of the scanned field affected. No fibrosis or inflammation scored 0 , up to one-third of the section affected scored 1, up to two-thirds 2 and more than two-thirds 3. Fibrosis was considered when there was thickening of the alveolar wall.

\section{Hydroxyproline estimation}

The heart and lungs were removed as a block and the heart detached. The lungs were dried thoroughly by pressing between tissue paper. Once all moisture was removed the lungs were placed in an eppendorf and immediately weighed. The weight of the lung was recorded, the sample labelled and put into liquid nitrogen. The samples were stored at $-80^{\circ} \mathrm{C}$ until ready for analysis. Hydroxyproline levels were measured, by using a high-pressure liquid chromatography (HPLC) method, as a means of assessing the amount of collagen in the lung tissue. Each sample was placed in a mortar and crushed into a powder using a pestle. The mortar was kept cool by being placed on dry ice and the lung was kept frozen using liquid nitrogen added onto the lung as needed. The powder obtained was stored in an eppendorf at $-80^{\circ} \mathrm{C}$ until ready for the next stage.

A known aliquot of the powder was weighed and placed in a Pyrex $\mathbb{R}$ tube. Three millilitres of $6 \mathrm{M} \mathrm{HCl}$ were added to the tube and hydrolysed at $110^{\circ} \mathrm{C}$ for $16 \mathrm{~h}$. The hydrolysate was mixed with activated charcoal for $45 \mathrm{~min}$ before being centrifuged at 5,000 revolutions per minute for $15 \mathrm{~min}$. One millilitre of the hydrolysate was taken off and filtered (type DA, pore size $0.65 \mu \mathrm{m}$; Millipore, Bedford, MA, USA) into a $1.5 \mathrm{~mL}$ microfuge tube, $10 \mu \mathrm{L}$ of this filtered solution was further diluted with $90 \mu \mathrm{L}$ water before $10 \mu \mathrm{L}$ of this was taken and used. This filtrate was dried using a centrifugal vacuum concentrator. The dried filtrate was reconstituted in $100 \mu \mathrm{L}$ of water buffered with $100 \mu \mathrm{L}$ of $0.4 \mathrm{M}$ potassium tetraborate and reacted with $100 \mu \mathrm{L}$ of $12 \mathrm{mM}$ 7-chloro-4nitrobenz-2-oxa-1,3-diazole in methanol. Samples were incubated in the dark for $20 \mathrm{~min}$ at $37^{\circ} \mathrm{C}$. The reaction was stopped by addition of $50 \mu \mathrm{L}$ of $1.5 \mathrm{M}$ hydrochloric acid and $150 \mu \mathrm{L}$ of $167 \mathrm{mM}$ sodium acetate in acetonitrile $(26 \% \mathrm{vol} / \mathrm{vol})$. Samples were filtered (pore size $0.22 \mu \mathrm{m}$ ) and $100 \mu \mathrm{L}$ of the filtrate was loaded in the column and eluted with an acetonitrile gradient to undergo reverse phase HPLC.

The peak areas in the chromatogram obtained were compared to standards and the hydroxyproline content calculated. Assuming lung collagen to contain $12.2 \% \mathrm{w} / \mathrm{w}$ hydroxyproline, the collagen in each lung was determined. Four aberrant results were excluded from the analysis, one from group $\mathrm{C}$, two from group $\mathrm{V}$ (one mislaid), one from group $\mathrm{BV}$.

\section{Statistical analysis}

Histological analysis and hydroxyproline estimation between the groups was compared using one-way analysis of variance. A post hoc multiple comparison with Bonferonni correction was performed to compare individual groups. An unpaired t-test for hydroxyproline estimation was performed between the individual groups. A $p<0.05$ was considered to be significant.

\section{Results}

Of the 30 mice in the experiment there were no premature deaths. The fibrosis and inflammation scores are shown in table 1. The fibrosis scores for the BV group were significantly higher (median 2.2 ) compared to the B (median 0), V (median 0.2), or C (median 0) groups. Similarly, the inflammation scores in the BV group were significantly higher (median 1.9) compared to the B (median 0.5), $\mathrm{V}$ (median 0.8) and C (median 0.2) groups (table 2). Post hoc multiple analysis showed that mice receiving both bleomycin and virus developed significantly $(\mathrm{p}<0.001)$ more fibrosis and inflammation. A representative selection of histological sections are illustrated in figures 1-5.

\section{Hydroxyproline estimation}

The lung weights, hydroxyproline and collagen content following removal and drying are shown in table 3. The bleomycin/virus lungs were the heaviest 
Table 1. - The histological fibrosis and inflammation score of the individual lung tissue

\begin{tabular}{lcc}
\hline Group & Fibrosis & Inflammation \\
\hline C1 & 0 & 0 \\
C2 & 0 & 1 \\
C3 & 0 & 0 \\
C4 & 0 & 0 \\
C5 & 0 & 0 \\
V1 & 1 & 2 \\
V2 & 0 & 1 \\
V3 & 0 & 1 \\
V4 & 0 & 0 \\
V5 & 0 & 0 \\
B1 & 0 & 2 \\
B2 & 0 & 0 \\
B3 & 0 & 0 \\
B4 & 0 & 0 \\
B5 & 0 & 1 \\
B6 & 0 & 0 \\
BV1 & 2 & 2 \\
BV2 & 3 & 2 \\
BV3 & 3 & 2 \\
BV4 & 3 & 2 \\
BV5 & 2 & 2 \\
BV6 & 3 & 2 \\
BV7 & 3 & 2 \\
BV8 & 2 & 2 \\
BV9 & 0 & 2 \\
BV10 & 0 & 1 \\
BV11 & 3 & 2 \\
BV12 & 1 & 1 \\
BV13 & 3 & 2 \\
BV14 & 3 & \\
\hline Sc0 & 0 & \\
\hline
\end{tabular}

Scores were marked 0-3. C: control; V: virus only; B: bleomycin only; BV: bleomycin and virus.

Table 2. - Summary of the histological fibrosis scores

\begin{tabular}{llllll}
\hline & $\mathrm{C}$ & $\mathrm{V}$ & $\mathrm{B}$ & $\mathrm{B} \& \mathrm{~V}$ & p-value $^{\#}$ \\
\hline Fibrosis & 0 & 0.2 & 0 & 2.2 & $<0.001$ \\
Inflammation & 0.2 & 0.8 & 0.5 & 1.9 & $<0.001$ \\
\hline
\end{tabular}

Data are presented as median values. C: control; V: virus only; B: bleomycin only; BV: bleomycin and virus. \#: analysis of variance.

with a median weight of $291.4 \mathrm{mg}$, a crude estimation of collagen content. There was no difference in collagen content between group C (mean $1.57 \mathrm{mg}$ ) and group B (mean $1.52 \mathrm{mg}$ ), $\mathrm{p}=0.78$. There was no difference between group $\mathrm{C}$ (mean $1.57 \mathrm{mg}$ ) and group $\mathrm{V}$ (mean $1.52 \mathrm{mg}$ ), $\mathrm{p}=0.8$ and there was no difference between group $\mathrm{C}$ (mean $1.57 \mathrm{mg}$ ) and group BV (mean $1.86 \mathrm{mg}$ ) $\mathrm{p}=0.16$. There was a significant difference in collagen content between group $\mathrm{B}$ and group $\mathrm{BV}, \mathrm{p}=0.04$. There was a trend towards significant difference between group $\mathrm{V}$ and group $\mathrm{BV}, \mathrm{p}=0.09$. There was no overall difference in the collagen content, $\mathrm{p}=0.79$, between the four groups (table 4).

\section{Discussion}

Previous studies in humans have shown an association of EBV with IPF. However, the practical

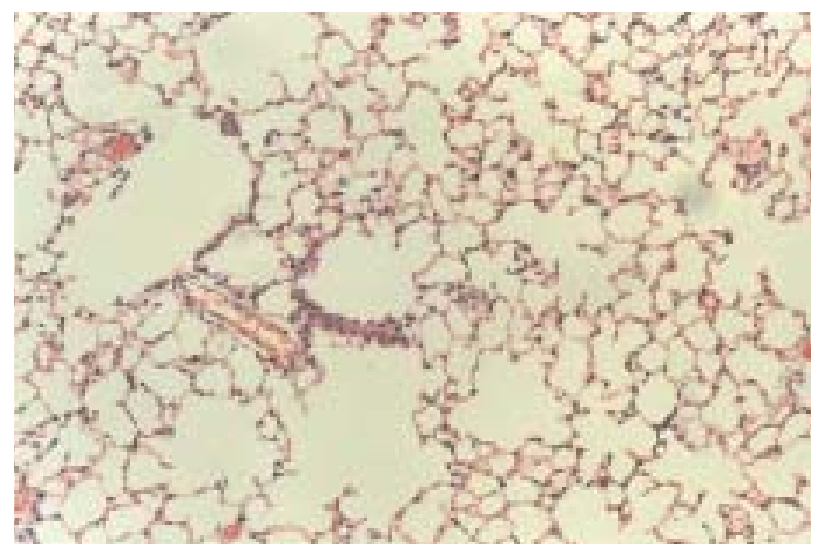

Fig. 1. - Histological section of lung from controls. The histology shows normal lung with no evidence of fibrosis or inflammation. This section is scored fibrosis 0 , inflammation 0 .

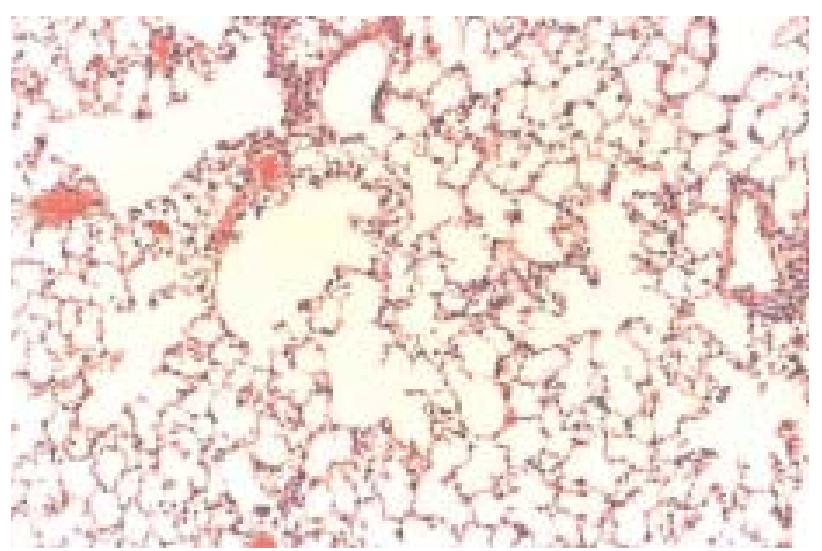

Fig. 2. - A section of lung from mouse given bleomycin. There are inflammatory changes in the alveolar wall but no signs of fibrosis. The inflammatory change involves about two-thirds of the scanned area. Score fibrosis 0 , inflammation 2 .

difficulties in obtaining human lung tissue potentially limits further studies of the relationship between viral injury and lung fibrosis. These experiments suggest that mice exposed to an exogenous lung injury, in the presence of an active viral infection, develop pulmonary

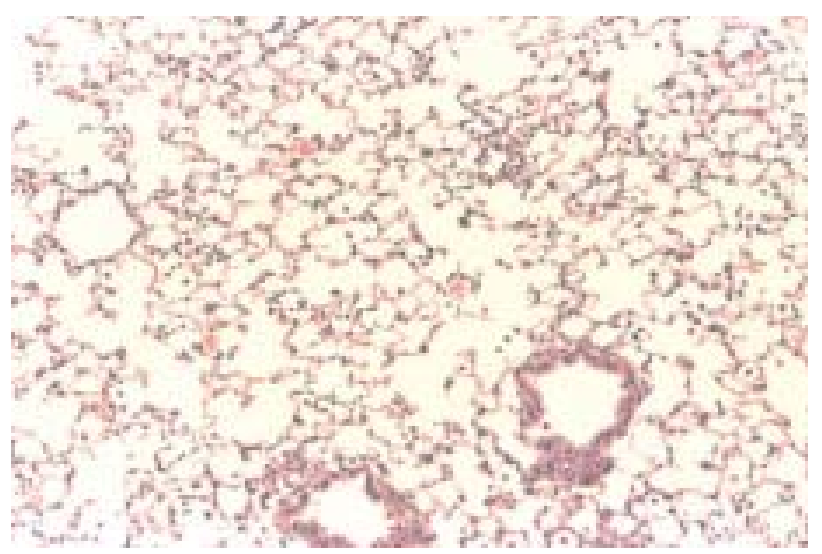

Fig. 3. - A section of lung from mouse given virus alone. A section of lung from mouse given virus only. There is a widespread inflammatory change with areas of thickened alveolar wall. This section scores fibrosis 1 , inflammation 2 . 


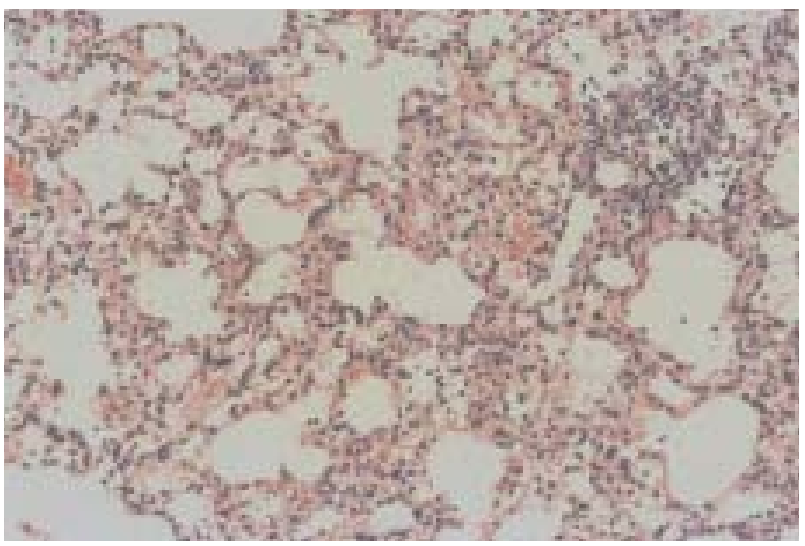

Fig. 4.-A section of lung from mouse given bleomycin and virus. There is gross thickening of the alveolar wall with lung distortion and loss of architecture involving at least two-thirds of the scanned area. Inflammatory changes are also present. This section scores fibrosis 3 , inflammation 2 .

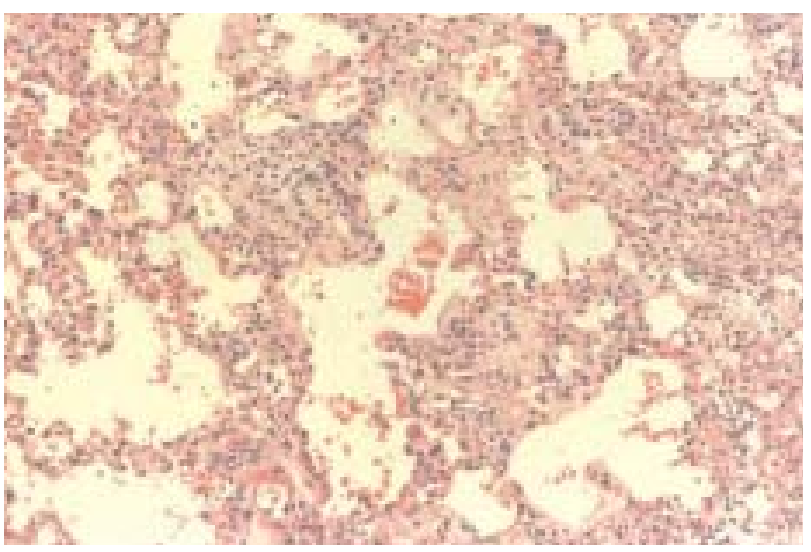

Fig. 5. - A section of lung from the mouse given bleomycin virus. There is complete loss of lung architecture. This section scores fibrosis 3, inflammation 2 .

fibrosis while mice receiving virus alone did not. The histological assessment shows that the bleomycinresistant $\mathrm{BALB} / \mathrm{c}$ mice who received both bleomycin and virus exhibited significantly greater pulmonary fibrosis and inflammation.

This mouse model was evaluated to specifically investigate the role of EBV in pulmonary fibrosis. MHV was chosen as an infecting agent since it behaves similarly in mice as EBV does in humans. The MHV genome consists of a $118 \mathrm{~kb}$ genome flanked by terminal repeat sequences. Genomic sequences have illustrated a number of genes with strong homology and a comparable location in both the genome of EBV and MHV [12]. For example, MHV produces proteins expressed during viral latency from the left hand of its genome which are similar to EBV-related small messenger ribonucleic acid proteins from EBV, derived from the same region of its genome and expressed during latency. STEWART et al. [13] emphasised the close relationship between MHV and EBV. They studied the MHV gycloprotein $\mathrm{B}(\mathrm{gB})$ and compared this to the EBV gB (gp110). This $\mathrm{gB}$ is unusual among the herpes group of viruses, and the strong similarities illustrate the close relationship
Table 3.-The dried lung weights, hydroxyproline and collagen content of the mice lungs

\begin{tabular}{lccc}
\hline Mouse & $\begin{array}{c}\text { Lung weight } \\
\mathrm{mg}\end{array}$ & $\begin{array}{c}\text { Hydroxyproline } \\
\mu \mathrm{g}\end{array}$ & $\begin{array}{c}\text { Collagen } \\
\mathrm{mg}\end{array}$ \\
\hline C1 & 141.6 & 9.69 & 1.13 \\
$\mathrm{C} 2$ & 160.4 & 9.48 & 1.13 \\
C3 & 148.2 & 20.60 & 1.99 \\
C5 & 106.3 & 18.34 & 1.70 \\
C6 & 146.8 & 18.81 & 1.86 \\
C7 & 150.5 & 18.63 & 1.64 \\
B1 & 165.6 & 12.41 & 1.17 \\
B2 & 187.0 & 11.96 & 1.72 \\
B3 & 128.2 & 18.24 & 1.47 \\
B4 & 137.9 & 15.18 & 1.53 \\
B5 & 166.5 & 12.76 & 1.53 \\
B6 & 163.3 & 16.17 & 1.88 \\
B7 & 135.0 & 19.11 & 1.39 \\
V1 & 165.2 & 15.05 & 1.49 \\
V2 & 219.7 & 13.22 & 1.57 \\
V3 & 266.3 & 16.59 & 2.88 \\
V4 & 248.4 & 10.06 & 1.74 \\
V5 & 219.3 & & \\
V6 & 207.7 & 20.09 & 1.79 \\
BV1 & 244.7 & 17.23 & 2.08 \\
BV2 & 240.2 & 13.69 & 1.58 \\
BV3 & 206.9 & 18.24 & 1.88 \\
BV4 & 197.2 & 17.20 & 1.77 \\
BV5 & & & \\
BV6 & 235.1 & 16.18 & 2.43 \\
BV7 & 175.8 & 18.85 & 1.55 \\
BV8 & 234.5 & 19.62 & 1.75 \\
\hline C: & B & & \\
\hline
\end{tabular}

C: control; B: bleomycin only; V: virus only; BV: bleomycin and virus.

Table 4. - The median lung weight upon harvesting and the median lung collagen content of the four groups

\begin{tabular}{lrrrrr}
\hline & C & \multicolumn{1}{c}{ V } & \multicolumn{1}{c}{ B } & BV & p-value $^{\#}$ \\
\hline $\begin{array}{l}\text { Dried lung } \\
\text { weight mg }\end{array}$ & 148.2 & 221.1 & 154.8 & 217.3 & $<0.01$ \\
$\begin{array}{c}\text { Collagen in } \\
\text { lung mg }\end{array}$ & 1.70 & 1.53 & 1.65 & 1.76 & 0.79 \\
SD & 0.73 & 0.23 & 0.61 & 0.56 & \\
\hline
\end{tabular}

C: control; V: virus only; B: bleomycin only; BV: bleomycin and virus. "\#: analysis of variance; ": median weight.

between EBV and MHV. In vivo MHV in the mouse results in splenomegaly $[15,16]$ and causes lymphomas. The virus persists in the lungs and epithelial cells and enters latency in B-lymphocytes very similarly to the activity of EBV in humans.

The blinded histology assessment applied a scoring system based on the percentage of a scanned section affected by fibrosis or inflammation. The minimum pathological change for a fibrosis score to be established was a moderate amount of thickening of the alveolar or bronchiolar wall. The scoring was therefore a robust technique as it eliminated the milder changes, which may be subject to arbitrary interpretation. As the pathologist was blinded to the groups over-scoring is unlikely. In the majority of the BV group there were clear changes of alveolar fibrosis with distortion of lung architecture. 
The results of this study may have been facilitated if alternative staining methods had been utilised to quantify the histological fibrosis. In particular, azan staining may have allowed a more accurate quantification of fibrosis. The biochemical analysis of hydroxyproline content was largely supportive of the histological findings but there was no overall difference in collagen content between the groups. A larger number of samples may have corrected for this as the lung weights were significantly larger in the BV group and there was significant difference in collagen content between the BV group (mean $1.86 \mathrm{mg}$ ) and the B group (mean $1.52 \mathrm{mg}$ ).

In humans, the mechanism by which EBV could contribute to the development or progression of IPF may be related to its effect on cell cycle proteins. Antigens produced during EBV replication in epithelial cells (e.g. EBNA5 and BZLF1) affect the function of cell cycle proteins such as p53 $[17,18]$. This in turn may disturb normal cell growth and division including that of epithelial cells. An intact lung epithelium is important in controlling normal cytokine function. A viral factor resulting in damage to the epithelium may lead to modification of the cytokine balance resulting in dysregulation of the repair process and hence the promotion of fibrosis.

This study demonstrates that viral infection with MHV alone does not result in pulmonary fibrosis. $\mathrm{BALB} / \mathrm{c}$ mice were chosen because they are inherently resistant to bleomycin suggesting that viral infection primes the normally resistant lung to bleomycin lung injury, therefore acting as a cofactor in disease development or disease progression. This is an important concept as immunosuppressive therapy is frequently administered to IPF patients potentially promoting viral replication within human lung tissue. Such viral replication may then provide a source of repetitive injury which is increasingly acknowledged as being a key factor in the pathogenesis of IPF. Furthermore, this concept may clarify why immunosuppression has largely failed to impact on disease progression in IPF while nonimmunosuppressive therapy such as antioxidants, colchicine and possibly interferon gamma have at least offered some encouraging results.

In summary, this study suggests that the presence of replicating virus may contribute to the development of fibrosis after an exogenous lung injury, and the model described may be useful in further investigating the pathogenesis of viral-mediated pulmonary fibrosis in humans.

Acknowledgements. The authors appreciate the support provided by G. Laurent for the completion of this study.

\section{References}

1. Miller JN. Infectious mononucleosis and fibrosing alveolitis. BMJ 1977; 1: 612.
2. Vergnon JM, Vincent M, Mornex JF, et al. Cryptogenic fibrosing alveolitis and Epstein Barr virus: an association. Lancet 1984; 2: 768-771.

3. Egan JJ, Woodcock AA, Stewart JP. Viruses and idiopathic pulmonary fibrosis. Eur Respir J 1997; 10: 1433-1437.

4. Lok SS, Egan JJ. Viruses and idiopathic pulmonary fibrosis. Monaldi Arch Chest Dis 2000; 55: 146-150.

5. Straus SE, Cohen JI, Tosato G, Meier J. Epstein Barr virus infections: biology, pathogenesis and management. Ann Intern Med 1993; 118: 45-48.

6. Yonemaru M, Kasuga I, Kusumoto H, et al. Elevation of antibodies to cytomegalovirus and other herpes viruses in pumonary fibrosis. Eur Respir $J$ 1997; 10: 2040-2045.

7. Hogg JC. Epstein Barr virus and cryptogenic fibrosing alveolitis. Thorax 1995; 50: 1232.

8. Egan JJ, Stewart JP, Hasleton PS, Arrand JR, Carroll $\mathrm{KB}$, Woodcock AA. Epstein Barr virus replication within pulmonary epithelial cells in cryptogenic fibrosing alveolitits. Thorax 1995; 50: 1234-1239.

9. Stewart JP, Egan JJ, Ross AJ, et al. The detection of Epstein Barr virus DNA in lung tissue from patients with idiopathic pulmonary fibrosis. Am J Respir Crit Care Med 1999; 159: 1336-1341.

10. Tsukamoto K, Hayakawa H, Sato A, Chida K, Nakamura H, Miura K. Involvement of Epstein Barr virus latent membrane protein 1 in disease progression in patients with idiopathic pulmonary fibrosis. Thorax 2000; 55: 958-961.

11. Stewart JP, Usherwood EJ, Rose A, Dyson H, Nash T. Lung epithelial cells are a major site of murine gammaherpesvirus persistence. J Exp Med 1998; 187: 1941-1951.

12. Efstathiou S, Ho YM, Hall S, Styles CJ, Scott SD, Gompels UA. Murine herpesvirus 68 is genetically related to the gammaherpesviruses Epstein Barr virus and herpesvirus saimiri. J Gen Virol 1990; 71: 13651372.

13. Stewart JP, Janjua NJ, Sunil-Chandra NP, Nash AA, Arrand JR. Characterization of murine gammaherpesvirus 68 glycoprotein $\mathrm{B}(\mathrm{gB})$ homolog: similarity to Epstein Barr virus gB (gp110). J Virol 1994; 68: 64966504.

14. Ashcroft T, Simpson JM, Timbrell V. Simple method of estimating severity of pulmonary fibrosis on a numerical scale. J Clin Pathol 1988; 41: 467-470.

15. Sunil-Chandra NP, Efstathiou S, Nash AA. Murine gammaherpesvirus 68 establishes a latent infection in mouse B lymphocytes in vivo. J Gen Virol 1992; 73 : 3275-3279.

16. Stewart JP, Usherwod EJ, Dutia B, et al. Immunobiology of murine gammaherpesvirus 68. Herpesvirus and Immunity 1998; 149-163.

17. Szekely L, Selivanova G, Magnusson KP, Klein G, Wiman KG. EBNA-5, an Esptein Barr virus encoded nuclear antigen, binds to the retinoblastoma and p53 proteins. Proc Natl Acad Sci USA 1993; 90: 54555459.

18. Zhang Q, Gutsch D, Keany S. Functional and physical interactions between p53 and BZLF1: implications for EB virus latency. Mol Cell Biol 1994; 14 : $1929-1938$. 